\title{
Francisco Rodríguez Cascante. Imaginarios utópicos. Filosofía y literatura disidentes en Costa Rica (1904-1945). San José: Editorial de la Universidad de Costa Rica, 2016, 287 páginas
}

\author{
Carlos Manuel Villalobos
}

Villalobos, C. M. (2021). Francisco Rodríguez Cascante. Imaginarios utópicos. Filosofía y literatura disidentes en Costa Rica (1904-1945). San José: Editorial de la Universidad de Costa Rica, 2016, 287 páginas. Revista de Filología y Lingüística de la Universidad de Costa Rica, 47(1), e44335. doi: https://doi.org/10.15517/rfl.v47i1.44335

\section{(9) $\mathbb{P Q \Theta \Theta}$}

Doi: https://doi.org/10.15517/rfl.v47i1.44335

URL: https://revistas.ucr.ac.cr/index.php/filyling/index 


\section{Reseñas}

Francisco Rodríguez Cascante. Imaginarios utópicos. Filosofía y literatura disidentes en Costa Rica (1904-1945). San José: Editorial de la Universidad de Costa Rica, 2016, 287 páginas

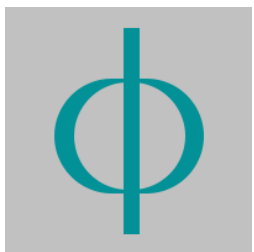

\section{Villalobos, Carlos Manuel}

Carlos Manuel Villalobos

carlos.villalobos@ucr.ac.cr

Universidad de Costa Rica, San José, Costa Rica

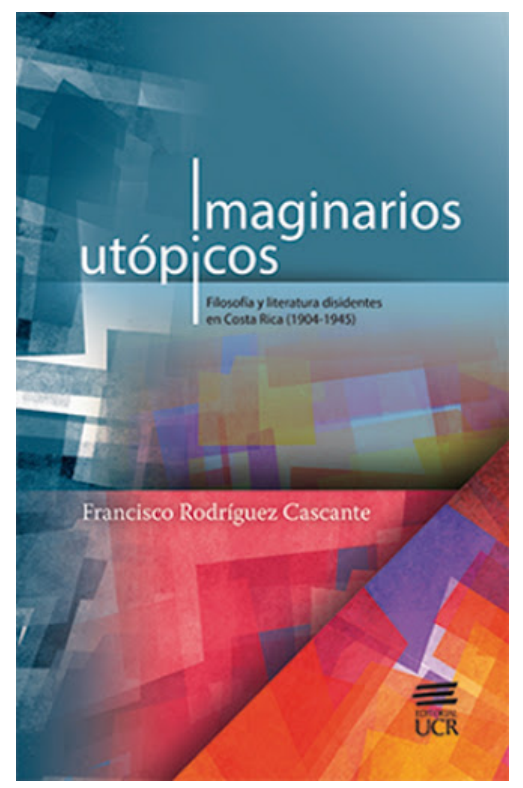

Rodríguez Cascante Francisco. Imaginarios utópicos. Filosofía y literatura disidentes en Costa Rica (1904-1945). 2016. San José. Editorial de la Universidad de Costa Rica. 287 páginaspp.

Revista de Filología y Lingüística de la Universidad de Costa Rica

Universidad de Costa Rica, Costa Rica

ISSN: 0377-628X

ISSN-e: 2215-2628

Periodicidad: Semestral

vol. 47, núm. 1, 2021

filyling@gmail.com

URL: http://portal.amelica.org/ameli/

jatsRepo/125/1251597028/index.htm

DOI: https://doi.org/10.15517/rfl.v47i1.44335 
En general, la institucionalidad literaria costarricense ha privilegiado un corpus compuesto por textos que tienen como principal referente lo nacional. Este canon aplica con más razón a propósito de los estudios que abarcan los periodos fundacionales del siglo XIX y los que se ubican a principios del XX. Frente a esta legitimación, el libro Imaginarios utópicos. Filosofía y literatura disidentes en Costa Rica (1904-1945) de Francisco Rodríguez Cascante explora un conjunto de textos disidentes -filosóficos y estéticos- ubicados en el período que va de 1904 a 1945 y que han sido poco estudiados por la historiografía nacional. La muestra es heterogénea y da cuenta de las cosmovisiones y contradicciones de la comunidad letrada de ese momento. Esta investigación evidencia que en este período no existió un pensamiento homogéneo alrededor del proyecto liberal oligárquico y que estos discursos confrontativos buscaron nuevos modos de imaginar el futuro.

Para explicar estas disidencias, Rodríguez aprovecha el concepto de "imaginario" que propuso el filósofo greco francés Cornelius Castoriadis. Para este autor, la realidad es una construcción simbólica que, de manera creativa, construyen los sujetos a través de la historia. Determina las normas, los valores, los lenguajes y los procedimientos colectivos; "es decir todas aquellas codificaciones consensuadas que posibilitan la comunicación y rigen la convivencia” (xvi-xvii). Adicionalmente, Rodríguez recurre al filósofo canadiense Charles Taylor quien explica que el imaginario remite al modo en que las personas imaginan su entorno social, la manera en que lo comparten con grupos amplios y posibilitan la construcción de las prácticas comunes.

Un término estratégico que, en este caso, adjetiva la noción de imaginario es el concepto de "utopía". Para ello, Rodríguez recurre a las fundamentaciones de autores como Arturo Andrés Roig, Fernando Aínsa, María del Rayo Ramírez Fierro y Horacio Cerutti, quienes han reflexionado sobre las implicaciones que tiene esta idea en América Latina, pues lo utópico se ha entendido como la imaginación de espacios alternativos. En el caso de los discursos que se estudian en este libro, los escenarios idealizados están determinados por las nociones de libertad, justicia social y valores humanistas, entre otros. Se manifiestan como "una tensión provocada por el rechazo a las condiciones sociales imperantes y los anhelos de su transformación" (xx).

En cuanto a su estructura, el libro se compone en dos partes y se divide en once capítulos. La primera, se titula "Teosofía y espiritismo: el pensamiento costarricense alternativo de principios del siglo XX" e incluye seis apartados. Está dedicada, sobre todo, al género ensayístico con discursos que dan cuenta de las principales líneas del pensamiento teosófico y espiritualista de autores como Roberto Brenes Mesén, Tomás Povedano, Omar Dengo, José Basileo Acuña, Rogelio Sotela, Víctor Manuel Cañas y Rogelio Fernández Güell, entre otros.

La segunda parte se titula "Sin fronteras: literatura y utopías" y se divide en cinco capítulos. Explora textos literarios (narrativa, lírica y teatro) que ponen su atención en aquellos imaginarios sociales que amplían las fronteras geográficas y culturales de la nación. En esta muestra, Rodríguez estudia la literatura "cuyo cronotopo transita entre Costa Rica y París" (xxxii); además, considera textos relacionados con el orientalismo, el hispanismo, el socialismo utópico, el espiritismo, la teosofía, el anarquismo, el espiritismo, el indianismo y el socialismo. Le interesan algunos casos de literatura dramática, "donde se estudian las relaciones entre constructores morales y relaciones sociales, así como los vínculos con las concepciones familiares, determinantes para la dramaturgia de principios del siglo XX" (xxxii). Entre los autores que se consideran en esta parte se encuentran Claridad Salazar, Carlos Gagini, Rafael Ángel Troyo, Moisés Vincenzi, María Fernández de Tinoco, Juana Fernández Ferraz y Eduardo Calsamiglia, entre otros.

El capítulo I estudia el proceso intelectual de Roberto Brenes Mesén. En su juventud este autor, tal y como se evidencia en su producción poética, creía que el progreso humano era posible mediante la ciencia y su método experimental. Sin embargo, su incursión en la masonería y la teosofía lo llevan a rechazar esta idea. A partir de este momento, cree que es posible convertir el misticismo en una epistemología del conocimiento y que la religión va más allá de lo meramente teológico. Estas perspectivas lo llevan a sostener una polémica con Carlos Gagini, quien, en nombre del mecanismo positivista, desacredita los postulados idealistas del 
pensamiento teosófico. Los entreveros de esta discusión le permiten a Rodríguez ahondar en las concepciones metafísicas de Brenes Mesén.

El capítulo II está dedicado a la figura de Omar Dengo, quien transita del anarquismo al espiritualismo. Este pensador había participado en la creación del Centro Germinal (1912), una agrupación de intelectuales con una visión anárquica y una clara consciencia socialista. Sin embargo, la admiración que siente por Roberto Brenes Mesén lo llevan a interesarse por el ideario metafísico. Dengo ingresa a la Sociedad Teosófica y a la masonería y aboga por una perspectiva panteísta. Una de las consecuencias de su vínculo con Brenes Mesén es su participación en la polémica contra Carlos Gagini. Le critica su pretensión de explicar los orígenes del ser humano a partir de una sociología genética de carácter positivista.

El siguiente capítulo está dedicado a otra polémica en la que se enfrentan la teosofía y la visión conservadora del catolicismo. La confrontación ocurre en 1916 y tiene como protagonistas a Tomás Povedano, un español radicado en Costa Rica, y al cura Rosendo Valenciano. Povedano es el fundador de la Logia Virya (1904), la primera de su género en Costa Rica. De esta deriva la Logia Dharana, que presidió Brenes Mesén; por lo tanto, este teósofo español es una autoridad que cuenta con los suficientes recursos para enfrentar la discusión. Povedano intenta convencer a los católicos de que la teosofía no contradice sus creencias, pero el sacerdote se opone a esta tesis y considera que el panteísmo teosófico es una apostasía. En total se emitieron cuarenta y cinco artículos donde quedó en evidencia el ímpetu conservador del clero costarricense y las dificultades de los teósofos para incidir en esta estructura ideológica.

En el capítulo IV se presenta la figura de un joven entusiasta que abraza la teosofía y hará una de las más amplias y mejores sistematizaciones de este pensamiento en Costa Rica. Se trata de José Basileo Acuña, quien desarrolla investigaciones sobre los estados del universo, la teoría antropológica, el superhombre, la evolución, la activación de la bondad y la apuesta por la raza latinoamericana, entre otros temas.

En el siguiente apartado, Rodríguez estudia la teoría del recogimiento que desarrolla Rogelio Sotela, quien reflexiona sobre la supraconciencia que alcanza el ser humano a través de la meditación. Por esta vía se logra un estado búdico "que vincula al ser humano con la divinidad" (97). En este mismo capítulo se analizan las ideas de Víctor Manuel Cañas, un joven estudioso de la teosofía que analiza la noción de superhombre, entendido como una conciencia predispuesta al infinitismo filosófico, caracterizado por "actos de iluminación capaces de demostrar tanto el plan divino como la necesaria vinculación del ser humano con Cristo" (103).

El último capítulo de esta primera parte está dedicado al espiritismo que desarrolla Rogelio Fernández Güell, así como sus planteamientos sobre el antiimperialismo. Se analiza el tema del auge del espiritismo en Costa Rica y sus intentos de unificar ciencia y religión. En este sentido, Fernández Güell creía que Jesús era un espiritista que había aprendido sus conocimientos durante una estadía en Egipto. A este imaginario metafísico se añade la utopía autonómica del hispanismo que se manifiesta también como una actitud antiimperialista.

La segunda parte del libro empieza con un ensayo sobre el modelo mimético-extranjerizante de la literatura costarricense. Aquí Rodríguez estudia lo que Abelardo Bonilla llamó como las formas de la novela ajenas al costumbrismo. En este caso, los textos considerados se alejan del realismo-costumbrista, "ya sea construyendo a Costa Rica como un no lugar o asumiendo como escenario Francia” (128). En esta cronotopía utópica se consideran los siguientes textos narrativos: El resplandor del ocaso (1918) de Francisco Soler; Celajes de Oro (1921) de Claridad Salazar de Robles; La caída del águila (1920) de Carlos Gagini; Corazón joven (1904) y Ortos (1903) de Rafael Ángel Troyo; Pierre de Monval (1935), La señorita Rodiet (1936) y Elvira (1940) de Moisés Vincenzi; El tesoro de Rajah (1923) de Arturo Castro Esquivel; Bajo el sol de América (1912) de Enmanuel Thompson y El espiritu del rio de Juana Fernández Ferraz.

El capítulo VIII está dedicado a la literatura espiritista producida por autores como Eduardo Calsamiglia, León Fernández Guardia, Carlos Gagini, Jenaro Cardona, Rogelio Fernández Güell, Jaime Gálvez y Moisés Vincenzi. Se considera el misterio de las apariciones del "más allá” en diversos relatos, así como la noción esotérica del mito de la Atlántida, entendida "como una sociedad utópica regida por ritos espiritistas” (180). 
En el siguiente capítulo, que corresponde al noveno, Rodríguez aborda el tópico del indianismo y la teosofía en la novelística costarricense. Para este punto considera las obras: Zulay y Yontá (1909) de María Fernández de Tinoco; El delfin del Curubici (1923) de Anastasio Alfaro; Arausi (1929) de Diego Povedano y Matla (1933) de Euclides Chacón Méndez.

Los capítulos finales están dedicados a otros imaginarios utópicos que incluyen, por una parte, la aspiración a una didáctica de lo moral a través de la dramaturgia y, por otra, a la idealización de la justicia social que defienden los modelos anárquico-socialistas. Los dramaturgos incluidos en el apartado que estudia la ejemplarización moral son Daniel Ureña, José Fabio Garnier y Eduardo Calsamiglia. Los autores que se dedican a explorar las utopías socialistas son José María Zeledón, Gonzalo Sánchez Bonilla y Rogelio Sotela.

En resumen, desde el punto de vista de la historiografía literaria costarricense, Imaginarios utópicos es un libro disidente que se interesa por los discursos que usualmente no abordan los instituyentes académicos, pues el canon oficial privilegia la huella de lo nacional. En consecuencia, al incluir estas voces subalternas, este libro amplía la heterogeneidad discursiva de la literatura costarricense y ofrece un nuevo camino para la comprensión de otras formas de pensar; es decir, el trayecto alternativo de los inconformes y sus imaginarios utópicos. 